\title{
Science Teachers' and Students' Perceived Difficult Topics in the Integrated Science Curriculum of Lower Secondary Schools in Barbados
}

Babalola J. Ogunkola (Corresponding author)

School of Education, University of the West Indies

P. O. Box 64, Cave Hill Campus, Barbados

Email: drbeejay@hotmail.com \& babalola.ogunkola@cavehill.uwi.edu

David Samuel

School of Education, University of the West Indies

P. O. Box 64, Cave Hill Campus, Barbados

E-mail: swanlake_sea@hotmail.com

Received: May 12, 2011

Accepted: June 2, $2011 \quad$ Published: October 1, 2011

doi:10.5430/wje.v1n2p17

URL: http://dx.doi.org/10.5430/wje.v1n2p17

The research is financed through the Study and Travel Grant from the University of the West Indies, Cave Hill Campus, Barbados

\section{Introduction}

In 1997, a statement was released from the 18th CARICOM Heads of Government Conference which, in effect, linked the economic development of the Caribbean region and its competitive advantage to the science and technological capabilities of its citizens. There are some serious implications of this statement for the continued economic growth and development of Caribbean economies especially in today's global economic environment of rapid technological growth and trade liberalization. An important one is the response of the education system to meet the challenges of producing a more scientifically and technologically literate population.

There has been a number of promising developments in science education in the region indicating at least an effort to respond to these challenges. At the primary and lower secondary levels, new curricula have been developed with more relevant approaches to science instruction. These include:

a.) An attempt to integrate science concepts with technology and societal themes.

b.) An emphasis on an inquiry-based approach to instruction.

At the upper secondary level, the Caribbean Examinations Council (CXC) continually revises the various science curricula of the Caribbean Secondary Education Certificate (CSEC) to more reflect the changing social, economic and technological environments of the region.

Despite these efforts, data obtained from secondary schools in the region on variables such as student enrollment in upper secondary science courses, student performance and interest in science as well as students' attitudes to science are not encouraging. For example, information from CXC reveal that in 2009, although the pass rates in the science subjects at the CSEC level were, as usual, relatively high (Biology-74\%, Chemistry-78\%, Physics-77\%, Integrated science- $89 \%$ ), this masks the recurrent problem of a significantly low percentage of students registering for these examinations. This can be seen when the number of students who sat examinations in the various science subjects (Physics-10 641; Chemistry-11 193; Biology-13 383; Integrated science-18 671) are compared to the number who sat English A. (88 929). In addition, despite the high pass rates, less than $50 \%$ of students who sat each of these examinations obtained the highest grades of I and II.

This situation is the same throughout the Caribbean including Barbados, and leads to the assumption that students lose interest in science in the lower secondary level with the result that many drop the science subjects in the upper secondary level. This loss of interest may be influenced by such factors as: 
a.) Difficulty of topics in the lower secondary science curriculum as perceived by students.

b.) Teacher factors such as strategies used to teach science, teacher attitude towards science teaching and teacher experience and qualifications.

c.) Location and perception of the academic standard of the secondary school attending.

d.) Students' study habits.

\subsection{Research problem}

The study was designed to investigate the perception of students and teachers of the difficult topics in the lower secondary school science curriculum of Barbados; if there were statistically significant differences in (a) students' perception and teacher perception of difficult topics and (b) students' perception of difficult topics based on their gender, interest in science, study habits and school location and school category; as well as to determine the inter-relationships among the four student variables (gender, interest in science, study habits, school location).

\subsection{Research questions}

a.) What are the perceptions of (a) students and (b) teachers of the difficult topics in the lower secondary school science curriculum?

b.) Is there significant difference in the topics perceived to be difficult by students compared to teachers?

c.) Is there significant difference in students' perceptions of difficult topics based on their gender, interest in science (low versus high interest), study habits (poor versus good), school location (rural versus urban)?

d.) Is there significant difference in students' perception of difficult topics based on their school category?

e.) What are the inter-relationships among the student variables: (a) gender and interest in science, (b) gender and study habits, (c) interest in science and study habits (d) interest in science and school location (e) study habits and school location?

\subsection{Operational definitions of variables}

a.) Student perception of difficult topics: Students' views of the ease or difficulty of understanding particular topics in the science curriculum after studying them.

b.) Teachers' perception of difficult topics: Teachers' views of the ease or difficulty of their own teaching of particular topics in the science curriculum.

c.) Student interest in science: Students' expressed desire and willingness to study science now and in the future in preparation for a possible future career in a science field.

d.) Study habits: The strategies and techniques used by students to understand the subject content covered in class.

e.) School location: Whether the school is located in an urban or rural area.

f.) School category: The perceived rank of the secondary school according to the academic ability of students admitted based on results of the Barbados Secondary School Entrance Examination and also on historical performance in CSEC examinations. Category 1 indicates the highest category and category 4 the lowest.

\section{Literature Review}

Research literature from countries around the globe provides evidence of much commonality in the types of problems and issues confronting science education, especially at the primary and secondary levels. Issues such as poor performance in science, low enrollment in science courses at the upper secondary and tertiary levels, as well as poor interest and attitudes to science have plagued the education systems of many countries for decades. Yet, despite numerous investigations into these areas, which served to inform various proposals and recommendations from reputable researchers and organizations on approaches and strategies to address them, these problems persist. Students are either still finding science too difficult, or, for various reasons, their interests are being drawn away from science.

\subsection{Perceived difficulty of science topics}

There are a variety of reasons why students, especially at the secondary level, may perceive science as difficult in comparison to other subject areas. It may be due to how the students perceive the subject based on their experiences with it, or even from information about the subject from other persons. Johnston (1991), commenting on the perceived difficulty of the subject area, indicated that this difficulty may be due to problems in perception and thinking of students. His analysis of the nature of perceived difficult topics led him to propose that this difficulty may be caused by 
complexity due to ideas and concepts existing at three different levels: macro and tangible, micro, and representational or symbolic. Using the concept 'water' to explain these levels; this concept can be taught at the macro level where students are able to observe the properties of water. It can also be taught at the micro level where, for example, students are taught that water consists of molecules of hydrogen and oxygen. At the representational level, these molecules can be represented as a symbol $\mathrm{H} 2 \mathrm{O}$.

These multiple ways of representing the same concept is common in secondary level science courses, especially chemistry and physics. Johnston proposed that the interaction of these three levels may cause overworking of the working memory hence causing difficulty in conceptualizing various areas in science. Although the spiral nature of the curriculum should allow the gradual progress of learning concepts from concrete (macro level) to abstract (micro and representational), very often in science teachers have to use all three levels in a single lesson.

Behar and Polat (2007) also point to misconceptions about science phenomena possessed by students as contributing to the difficulty of certain science topics. Chiappetta and Koballa (2006) defined misconceptions or alternative conceptions as ideas about phenomena that students bring to the classroom that does not correspond well with the scientific knowledge to be taught. They added that these alternative conceptions are tenacious and resistant to change by conventional teaching strategies. So these misconceptions may, according to Behar and Polat (2007), cause misunderstandings in certain science topics. This may especially be the case if the teaching strategies used by teachers are not adequate to allow for conceptual change.

A related argument put forward by Behar and Polat (2007) concerns the many terms and symbols used in the teaching of various science concepts. Many such terms are new to the students and so cannot be linked to their cognitive structures which, according to Behar and Polat, may also cause information overload in the working memory. In addition, some terms are known by students, but in a different context and with a different meaning to that used in science. An example is the concept of 'work'. Confusion may result which adds to the perception of difficulty of the area of content.

Key factors in facilitating an effective learning environment in the science class are the teaching strategies used by teachers. As early as 1910, John Dewey criticized science teaching of the day as giving too much emphasis to the accumulation of information rather than to an effective method of inquiry (Bybee, Trowbridge and Powell, 2008). Unfortunately, this argument appears to be as relevant today as it was then. Many times, teachers use the excuse of overloaded science curricula to explain their reliance on strictly didactic methods of teaching. Though these claims may have some merit, these teaching strategies may in effect, portray the subject as difficult to many students. Behar and Polat (2007) alluded to this when they identified the passive roles of students in the classroom and their perception of the teacher as the only source of knowledge, as contributing to the perceived difficulty of science topics.

\subsection{Students'interest in science}

Zikszentmiholyi and Hermenson (1995) provided a definition of interest as referring to a differential likelihood of investing energy in one set of stimuli rather than others. This definition is applicable to situations in the classroom where the interests of students in academic areas are reflected in actions such as time and effort spent studying a particular subject, willingness to engage in additional activities involving the subject area besides that given by the teacher, and voluntarily selecting the subject for further study. Various researchers have indicated positive relationships between student interest and learning (Logan and Skamp, 2005; Trumper, 2006; Elster, 2007). Simpson et al (1994) pointed to various research results (Gardner, 1975, 1996; Schibeci, 1944) which indicated the importance of cultivating students' learning interests about science.

Despite this evidence of the importance of student interest in science, especially as it relates to their academic achievement, studies worldwide have revealed that interests in, or attitudes towards science declines during students' secondary years (Jenkins and Pell, 2006; Osborne et al, 2003; Schmidt, 2000). What is unclear are the specific reasons for this decline. Researchers have identified a number of factors that may have an impact on students' interest in specific subjects. For example, Krapp (2002) identified a significant decline in interest in physics, chemistry and mathematics as students progress through secondary school. He also notes that this decline is especially pronounced for girls. Analysis of results from a 'Relevance for Science Education Project (ROSE)' undertaken in countries throughout Europe from 2003-2008 revealed that the number of students regarding science subjects, in particular physics and chemistry, as difficult has increased (Gedrovics, Mozelka and Cedere, 2010). There has also been a persistent decline in post-compulsory high school science enrollment worldwide over the last two decades (Trumper, 2006).

\subsubsection{Gender difference in interest in science.}

It is particularly noteworthy that a variety of researchers also found significant gender differences in attitudes towards, 
and interest in science, with girls losing interest faster than boys in secondary schools (Krapp, 2002; Trumper, 2006; Elster, 2007). Logan and Skemp (2008) indicated that these gender differences were most likely to be connected with a number of variables related to classroom experiences, including pedagogical variables.

\subsection{Students'study habits}

An important part of the learning process at all levels of the education system is the studying of the content covered in lessons by students. It is an accepted notion that, generally, students will not gain a thorough grasp of content simply from participation in a lesson, whether actively or passively. They must allocate time for additional activities such as review of the content covered, doing additional reading and exercises, doing homework etc. In other words they study. Studying can be done individually or in a group. It is especially important, and generally more frequently done, in preparation for examination.

The amount of studying done by a student should therefore positively correlate to the student's performance on an examination for which he or she studied for. In the context of this study, it should also negatively correlate with the student's perception of the difficulty of science concepts covered. Nonis and Hudson (2010) makes the distinction between study time, as measured by the amount of time spent studying per day, and study habits which are the strategies and techniques used by students to study. Nonis and Hudson found in their study on college business students, that there was not a significant direct relationship between study time and academic performance. They reasoned that study habits moderated the relationship between study time and academic performance. For example, students who employed study habits where they were better able to concentrate without their minds wandering off performed better in the short and long term.

Ogunkola and Fayombo (2009), in a study on academic achievement of secondary school students in Barbados, found statistically significant differences in students' achievement in favor of students with good study habits compared to those with poor study habits. They also found a significant positive relationship between study habits and interest in science. Based on the assumption that academic performance would negatively correlate with perception of difficult topics in science, then one can conclude that this negative correlation would also apply to the relationship between study habits and the perception of difficult topics in the science curriculum.

\subsection{School location and category}

A number of secondary schools in Barbados are located either in the capital city of Bridgetown or in its vicinity. These are urban schools. Schools located in other parishes away from the capital city are referred to as rural. Ogunkola and Fayombo (2009) also found statistically significant differences in students' science achievement in favor of urban schools as compared to rural schools. The reasons for this may be varied and complex but is probably related to differential access to resources required for quality teaching and learning.

Although all public secondary schools in Barbados should be on a level playing field in terms of resource allocation and the perception of the quality education received from them, in reality they are not. According to Leacock, Thompson, Burnett and Obidah (2007), secondary schools are ranked into four categories based on the quality of student intake according to the results of the Barbados Secondary School Entrance Examination (BSSEE). The order of ranking is from zone 1 as the highest ranked schools and zone 4 the lowest. They also added that the CSEC results over the last seven years from the various secondary schools seem to reflect the academic achievement of the students who entered these schools based on the BSSEE. So category 1 schools had the highest percentage passes, followed by category 2 , and then a mixture of categories 3 and 4 schools. Clearly, there is likely to be some significant relationship between school category and the perception of difficult topics in the science curriculum.

\subsection{Focus of the study}

From this discussion, there seems to be strong correlations between the perception of students of difficult topics in the science curriculum and student factors such as interest in science, gender, study habits, school location and category. These relationships have to be understood and taken into consideration in order to tackle problems related to declining enrollment and poor performance in science courses. This study is designed to investigate them.

\section{Research Methodology}

The study was designed to determine the perception of students and teachers of secondary schools in Barbados of the difficult topics in the lower secondary school science curriculum, and the relationships of some student-related variables on student perception of difficult topics. Data collection and organization procedures were therefore selected to allow for quantitative techniques to be used in the analysis of data.

\subsection{Population}


The population for the study consisted of students currently attending secondary schools in Barbados who have recently completed the science curriculum at the lower secondary level. These students were therefore currently in fourth and fifth form. The population also consisted of science teachers in these secondary schools who are currently teaching the lower secondary school science curriculum.

3.2 Selection of sample

\subsubsection{Selection of schools}

Eight secondary schools were purposively selected for data collection based on the following criteria:

a.) An equal number of urban and rural schools were to be selected.

b.) Selected schools should be in as wide a geographical area as possible.

c.) Schools from each of the four zones categorized based on student academic performance had to be selected.

d.) Most convenient for the researchers based on factors such as the presence of a suitable contact person in the school and ease of transportation.

Table 1 indicates the schools selected as well as their zone and location.

$<$ Table 1 about here $>$

\subsubsection{Selection of sample}

A sample of 200 fourth form students from the six schools and eight fifth form students were selected as participants for the study. The fourth form students were selected to provide responses to the questionnaire items while the fifth form students were selected for a focus group interview.

Stratified random sampling was used to select 25 fourth form students from each school. Table 2 below shows the number of students selected from each school classified according to gender.

$<$ Table 2 about here $>$

Convenience sampling was used to select the fifith form students for the focus group interview since they formed the lessons class of one of the researchers on this study.

The students were from a variety of secondary schools in category 1.

The total population of science teachers who presently teach the lower secondary curriculum at the six schools was purposively selected as the sample. There were 30 teachers selected distributed according to school and gender as shown in Table 3.

$<$ Table 3 about here $>$

\subsection{Instruments}

\subsubsection{Students' questionnaire}

This instrument consisted of three sections.

a.) An interest scale: This consisted of 15 items arranged in a Likert scale and constructed to measure the level of students' interest in science. This was used to answer research questions 3, 4, and 5.

b.) A study habits inventory: This consisted of 15 items arranged in a two column Likert scale (agree/disagree) constructed to measure students' study habits. This was used to answer research questions 3, 4, 5.

c.) A topic difficulty scale: This consisted of 26 science topics arranged in a rating scale. Students were asked to rate how difficult or easy they found each topic. The topics were selected from the 3rd level of the lower secondary school science curriculum. This was used to answer research questions 1,2,3 and 4.

\subsubsection{Teachers questionnaire}

This instrument consisted of two sections.

a.) Demographic information to obtain information on years of teaching experience and qualifications.

b.) Topic difficulty scale: This consisted of the same 26 science topics on the students' questionnaire arranged to measure teachers' perception of the difficulty of teaching the topics. This was used to answer research questions 1 and 2.

\subsection{Focus group interview schedule}

This consisted of a number of open-ended questions used to stimulate discussion and obtain information from students 
on their level of interest in science, their purposes of doing science, their perceptions of the difficulty of science, their study habits and their perceptions of their teachers' influence on their interest in science. This was used to supplement the responses received from the questionnaires to obtain a more in-depth analysis of the study's variables for more coherent discussion and conclusions.

\subsection{Validity and reliability of the instruments}

Content and construct validity for the teachers' and students' questionnaires were obtained by thorough analysis of the items by two experts in science education at the Cave Hill Campus of the University of the West Indies. Based on their comments and suggestions, a number of alterations were made to the instruments.

For internal consistency of the questionnaires, split-half reliability was determined by pilot testing both questionnaires using 4th form students as well as their teachers at a school which did not form part of the sample. For the students' questionnaire, a split-half reliability coefficient of $71 \%$, while for the teachers, a split-half reliability coefficient of $73 \%$ indicated that both questionnaires had internal consistency reliability.

\subsection{Data collection procedures}

Letters were initially sent to the principals of the eight schools informing them of the nature of the research and asking their permission to use their school for the collection of data. After permission was received, the questionnaires were delivered to each school by the researchers. The questionnaires were left with a contact person for distribution. Questionnaires from six of the schools were received a week later.

\subsection{Data analysis procedures}

\subsubsection{Research question 1}

Descriptive statistics were used to obtain numerical measures of the students' and teachers' perceptions of difficult topics in the science curriculum. For each topic, an index of relative difficulty was calculated based on a formula originally produced by Johnstone and Mahmoud (1980). For the students:

$$
\text { Index of relative difficulty }=\frac{N_{d} \times 100}{N_{t}-N_{n}}
$$

Where Nd represents the number of students who found the topic difficult, Nt represents the total number of students in the sample, and Nn, the number of students who had not yet studied the topic. For the teachers, the formula was adapted as follows:

$$
\text { Index of relative difficulty }=\frac{\underline{N}_{d} \times 100}{N_{n}-N_{t}}
$$

Where Nd represents the number of teachers who found the topic difficult to teach, $\mathrm{Nn}$, the number of teachers in the sample and Nt the number of teachers who had never taught the topic. The index of relatively difficulty obtained was taken as a measure of the perception of students or teachers of the difficulty of a particular topic.

\subsubsection{Research question 2}

Since the data collected indicated that very few of the teachers found any of the topics difficult to teach, descriptive statistics was therefore used to compare the topic difficulty indices for the students and the teachers.

\subsubsection{Research question 3}

A general index of topic difficulty was calculated for each student using the formula:

$$
\mathrm{TDI}=\frac{\underline{\mathrm{N}}_{\mathrm{sd}} \times 100}{\mathrm{~N}_{\mathrm{st}}-\mathrm{N}_{\mathrm{sn}}}
$$

Where $\quad$ Nsd $=$ the number of topics each student found difficult

Nst $=$ the total number of topics in the student questionnaire

Nsn $=$ the number of topics not done by a particular student.

The data obtained for the student interest scale was coded for each item where 4 represented high interest and 1, low interest. The data was tabulated and an overall mean obtained for each student. A mean of 1.0 to 2.5 was taken to represent low interest, and above 2.5 to 4.0 was taken to represent high interest. The data from the study habits inventory was also coded for each item where 1 represented poor habits and 2, good habits. The data was tabulated and an overall mean found for each student. A mean of 1.0 to 1.5 was taken to represent poor study habits, and above 1.5 to 2.0 , good 
study habits.

The $\mathrm{T}$ test for independent samples was then used to determine if there was a significant difference in students' perception of difficult topics based on their gender, interest in science, study habits, and school location.

\subsubsection{Research question 4}

One way analysis of variance was used to determine whether there were any significant differences in students' perception of topic difficulty based on their school category.

\subsubsection{Research question 5}

Contingency table and chi squared analysis was used to detect any inter-relationships between the student variables: gender, interest in science (high and low), study habits (good and poor), school location (urban and rural) and school rating (high performing and low performing).

\section{Data Analysis}

4.1 What are the perceptions of (a) students and (b) teachers of the difficult topics in the lower secondary school science curriculum?

The index of topic difficulty for students ranged from a low of $6.67 \%$ to a high of $38.7 \%$. The topics indicating the highest levels of difficulty were in the areas of physics and chemistry i.e. role of sound in food laboratory (38.7\%), role of gases in food preparation and preservation (37.9\%), planning and designing experiments on physical and chemical changes (35.3\%), Physical and chemical changes in the home (25.7\%), Components of the air (25.3\%), Energy transformation (23.4\%), Uses of gases in the atmosphere (23.1\%) Energy conservation $(21.5 \%)$ Types of chemical reactions $(20 \%)$ chemical tests for gases $(19 \%)$, heat transfer $(15.4 \%)$ and forms of energy $(15.3 \%)$, and characteristics of acids and bases (14.3\%) and properties of sound (13.7\%).

Topics with relatively low measures of difficulty indices were in a variety of subject areas but mainly biology and environmental science. Biology topics such as nutrients, food groups, diet, structure of the eye, eye diseases and structure of the ear had topic difficulty indices ranging from $6.67 \%$ to $12.5 \%$. Also with low measures of topic difficulty were the environmental science topics of recycling and pollution. However the chemistry topics of neutralization (11.8\%), $\mathrm{pH}$ and indicators (13.5\%), reflection and refraction (11.9\%), also had relatively low indices of topic difficulty.

Analysis of the focus group interview indicated similar findings. There was general agreement among the students that although science was an interesting subject, it could be quite difficult at times especially because of the teaching strategies used. Biology was comparably less difficult than physics or chemistry. It was more interesting and easier to study because it mainly involved studying the human body while many of the concepts taught in physics and chemistry were abstract and not experienced in every day life.

\subsection{Is there significant difference in the topics perceived to be difficult by students compared to teachers?}

Unlike the students, the teachers generally indicated little difficulty in teaching most of the listed topics. Most of the topics had a $0 \%$ difficulty level and the others ranged from $6.7 \%$ to $14.3 \%$. Table 4 shows a comparison of teachers and students' topic difficulty indices for the various topics.

For most of the topics, the students had a significantly higher level of TDI than the teachers. The exceptions were neutralization, $\mathrm{pH} /$ indicators, and reflection and refraction.

4.3 Is there significant difference in students' perceptions of difficult topics based on their gender, interest in science (low versus high interest), study habits (poor versus good), and school location (rural versus urban)?

Table 5 shows that a significant difference in topic difficulty indices was only indicated between students with low interest compared to students with high interest in science.

\section{$<$ Table 5 about here $>$}

4.4 Is there significant difference in students' perception of difficult topics based on their school category?

Table 6 shows that a significant difference in students' perception of topic difficulty was observed based on school category. Students in category 1 recorded the lowest perception of topic difficulty, followed by 2 , then 4 and then 3 .

$<$ Table 6 about here $>$

4.5 What are the inter-relationships among the student variables: (a) gender and interest in science, (b) gender and 
study habits, (c) interest in science and study habits (d) interest in science and school location (e) interest in science and school category $(f)$ study habits and school location $(g)$ study habits and school category?

Table 7 shows that the only significant relationship observed is that of gender and interest where it was observed that $45 \%$ of females had a high interest in science compared to $24.5 \%$ males.

$<$ Table 7 about here $>$

\section{Discussion}

\subsection{Summary of findings}

5.1.1 The perceptions of students of the difficult topics in the lower secondary school science curriculum

A wide range of difficulty levels were obtained for the various topics identified. Most students generally found the highest levels of difficulty in physics and chemistry concepts such as: components of the air, energy, and physical and chemical changes. The biology areas of healthy lifestyles, light and the eye, and sound and the air were found to be comparably easier. The focus group interview supported these findings since the students generally thought that biology concepts were more interesting and easier to study than physics and chemistry concepts. They indicated that biology concepts were more realistic and relevant to them compared to many concepts in physics and chemistry which tended to be very abstract.

5.1.2 Is there significant difference in the topics perceived to be difficult by students compared to teachers?

Unlike the students, the teachers generally indicated little difficulty in teaching most of the listed topics. The topics where a minority of teachers indicated difficulty were: acids and bases, light and the eye, sound and the ear, energy, and physical and chemical changes.

5.1.3 Is there significant difference in students' perceptions of difficult topics based on their gender, interest in science, study habits and school location?

The only significant difference observed was in students' perception of difficult topics based on their interest in science with students with high interest having a significantly lower perception of topic difficulty compared to those with low interest.

5.1.4 Is there significant difference in students' perception of difficult topics based on school category?

A significant difference in students' perception of topic difficulty was observed with students in category 1 recording the lowest perception followed by category 2 , then 4 and then 3 .

5.1.5 What are the inter-relationships among the various categorical student variables?

The only significant relationship observed is that of gender and study habits where it was observed that $45 \%$ of females had a high interest in science compared to $24.5 \%$ males.

\subsection{Discussion of findings}

Based on the large numbers of students that drop the pure science subjects at the secondary level, there is little doubt that students generally find secondary science difficult. The findings of this study indicate that certain science topics are perceived to be more difficult than others, and so issues related to the teaching of these topics may be a major contributor to the difficulties experienced by students in the learning of science generally. It was found that many of the areas of science that students experience difficulties with are in the subjects of physics and chemistry. This is supported by the research of Johnston (1991) which theorized that difficulties may be caused by complexity due to ideas and concepts existing at micro, macro and symbolic levels. These multi-level conceptual frameworks are more common in physics and chemistry than in biology. This is especially the case since concepts at the micro and symbolic levels are normally very abstract and so it is difficult for a teacher to provide concrete experiences for the students to facilitate more effective learning. The students in the focus group interview illustrated this when they identified biology concepts as being more relevant to them and easier to study than physics or chemistry concepts.

A related argument is the many new terms and symbols used in physics and chemistry compared to biology. Behar and Polat (2007) alluded to this as an added source of difficulty in science compared to other subject areas. It is not only the expectation that students should commit to memory these terms and symbols, but also that some of the terms are also used in the students' everyday lives and even studied in other subject areas but with a completely different meaning than that in science. Behar and Polat indicate that this may be a source of misconceptions for students adding to the difficulty of the subject area.

The students in the focus group interview also indicated that the teaching strategies generally used by teachers may 
actually contribute to students' perception of the difficulty of science. Behar and Polat (2007) supports this view when they indicated that the passive nature of students in the classroom combined with the perception that the teacher is the only source of knowledge makes science as a subject unappealing and uninteresting. So the perception of difficulty may also be due to this lack of adequate engagement in science activities. If teachers are suitably trained in using the recommended inquiry based approaches, and they actually use it in their classrooms, then this may reduce this perception of difficulty in science. The findings do indicate that generally the teachers do not find the science topics identified in the study as difficult to teach. This may not only mean that the teachers have a thorough grounding in these content areas, but also that they are of the view that their teaching methods are appropriate enough for the students to grasp the subject matter. The findings of this study indicate that this may not be accurate.

The study found no significant difference in students' perception of difficult topics based on their gender, study habits and school location. With reference to gender, this supports the findings of Ogunkola and Fayombo (2009) that there was no significant statistical difference in Barbadian secondary school students' science achievement based on their gender. Also, with reference to study habits, Nonis and Hudson (2010) found, in their study on college business students, that there was not a significant direct relationship between study habits and academic performance. So if the negative correlation is assumed between perception of difficult topics and academic achievement, then this supports the findings of this study. However, contrary to the findings of this study, Ogunkola and Fayomba (2009) found statistically significant differences in students' achievement in favour of students with good study habits compared to those with poor study habits. It should be noted that an important factor related to study habits is study time. This variable may be even more important as contributing to academic achievement than study habits. Nonis and Hudson actually identified study habits as simply moderating the relationship between study time and academic achievement. With reference to school location (urban or rural), Ogunkola and Fayomba also found statistically significant differences in science achievement in favor of urban schools compared to rural schools.

So far, this discussion has actually assumed some kind of indirect correlation between perception of topic difficulty and academic achievement. It has to be noted that this correlation may be problematic at best since a high perception of topic difficulty may not necessarily mean that a student's academic performance would be low. A student may find science very difficult but apply the necessary effort to do very well in it. So although the findings of Ogunkola and Fayomba (2009) serves as a good comparison to the findings of this study, care must be taken in using the findings of this study to support or contradict the findings of Ogunkola and Fayomba.

This study found statistically significant differences in students' perception of difficult topics based on their interest in science with students with high interest having a significantly lower perception of topic difficulty. Many researchers have found related findings of positive relationships between student interest and learning (Logan and Skemp, 2005, Trumper, 2006, Elster, 2007). However, there are also many findings that this interest declines as students pass through the secondary school years (Jenkins and Pell, 2006, Osborne et al, 2003, Schmidt, 2000).

A significant difference in students' perception of topic difficulty was observed based on the category of school the students were attending. The categories are assigned based on the performance of students entering the schools at the BSSEE with category 1 the highest and category 4 the lowest. Students in category 1 recorded the lowest perception of topic difficulty, followed by zone 2, then zone 4 and finally zone 3. These findings are generally what was to be expected based on the research of Leacock, Thompson, Burnett and Obidah (2007) where it was found that CSEC results over the last seven years generally reflected what was expected based on school category. The highest percentage pass was from schools in category I followed by schools in category 2 and then a mixture of category three and four schools.

The only significant relationship found among the independent variables was between gender of students and interest in science. It was found that the female students in the sample generally had significantly higher interest in science than male students. Even though the findings did not indicate gender differences in perception of difficult topics, this is not necessarily contradictory to the findings on differences in interest since the possession of high interest in science is not necessarily an indication of how difficult a student finds the subject. The research literature over the last decade has produced contradictory findings when investigating the relationships between gender and academic achievement or factors related to academic achievement like interest. There is however a general perception in the Caribbean that female students in secondary schools are more serious in their approach to their studies and more interested in their work compared to their male counterparts, and this is many times reflected in better academic performances. This study seems to corroborate this.

\subsection{Limitations of the findings}

The data was collected during the last two weeks of the school term. Most of the schools were engaged in a number of activities such as examinations, speech days etc. So there was a measure of difficulty in selecting students and actually 
administering the questionnaire. In the end, only 133 questionnaires were returned from six schools. This fairly low response rate would have affected the findings.

\subsection{Conclusion and recommendations}

It is important for educators and curriculum development officials to have an understanding of the reasons why so many students in the lower secondary school find science a difficult subject and quickly lose interest in it. Two possible reasons were identified in this study. The first has to do with the nature of many science concepts taught in the secondary schools. These concepts are very abstract in nature and many times little effort is made to present them to the students in a concrete way, e.g. with the use of models, which may lead to an easier understanding of the abstract concepts. More of these concepts are in the physics and chemistry areas of science compared to biology areas. The second focuses on the teaching strategies used in the science classes. In this study, even the students called into question the teaching strategies used that are, according to them, 'boring' with very little effort being made to present the material in an interesting and relevant way.

It is therefore recommended that principals, curriculum officers, and teachers should reacquaint themselves with the inquiry-based approaches recommended for science instruction and do their part in seeing that the curriculum is implemented using these approaches. The 'buzz' word now in the education circles in Barbados is constructivism. This is a promising development. However, it is doomed to failure if strategies are not put in place for effective monitoring of the implementation of the curriculum using this approach. A reliance on examinations alone for evaluating the curriculum is inadequate. The teachers must be made to step up and use the strategies that they were trained to use. Only then will students see relevance and meaning in science concepts even though they may be abstract.

The study also highlighted the importance of cultivating students' interest in science since it is significantly related to their perception of topic difficulty. It probably should not be left for the students to develop that interest on their own. The science departments of secondary schools in collaboration with the Ministry of Education must plan programs and interventions that not only show the importance of science in national development, but also exposes students to the possibilities of meaningful and lucrative careers in science. Attention must also be paid to the male students who this study indicated as having an even lower level of interest than female students.

\section{References}

Behar, M; Polat, P (2007). The science topics perceived difficult by pupils of primary 6-8 classes. Diagnosing the problems and remedy solutions. Educational Sciences: Theory and Practice. 7(3). 1113-1130.

Bybee, R.W; Powell, J.C., Trowbridge, L.W. (2008). Teaching Secondary School Science. Strategies for Developing Scientific Literacy. 9th Ed.; Pearson:Merril Prentice Hall; Ohio.

Chiappetta, E.L., Koballa Jr, T.R. (2006) Science Instruction in the Middle and Secondary Schools. Developing Fundamental Knowledge and Skills for Teaching; 6th ed.; Pearson:Merrill Prentice Hall; Ohio.

Csikszentmihalyi, M., \& Hermanson, K. (1995). Intrinsic motivation in museums: Why does one want to learn? In J. H. Falk \& L. D. Dierking (Eds.), Public institutions for personal learning: Establishing a research agenda (pp. 67 77). Washington, DC: American Association of Museums.

Elster, D. (2007). Student interests - The German and Austrian ROSE survey. Journal of Biological Education, 42(1), 5-11, http://dx.doi.org/10.1080/00219266.2007.9656100

Gedrovics, J.; Mozelka, D.; Cedere, D. Alteration of students' interest in science topics in Latvia, 2003-2008. Problems in Education in the 21st Century. 22. 45-54.

Johnstone, A. (1991). Why science is difficult to learn? Things are seldom what they seem. Journal of Computer Assisted Learning, 7, 75-83, http://dx.doi.org/10.1111/j.1365-2729.1991.tb00230.x

Krapp, A. (2002). An educational-psychological theory of interest and its relation to SDT. In E. L. Deci \& R. M.Ryan (Eds.), Handbook of self-determination research (pp. 405-426). Rochester, NY: University of Rochester.

Leacock, C.J.; Thompson, B,; Burnett, A.; Obidah, J. (2007). The academic achievement of Barbados public primary and secondary schools: 1999-2005. A comprehensive report. The University of the West Indies Education Evaluation Centre, Cave Hill Campus, Barbados.

Logan, M; Skamp,K (2008). Engaging children in science across the primary secondary interface: Listening to the 
students' voice. Research in Science Education. 38. 501-527, http://dx.doi.org/10.1007/s11165-007-9063-8

Nonis, S.A; Hudson, G.I. (2010). Performance of college students: Impact of study time and study habits. Journal of Education for Business. 85. 229-238, http://dx.doi.org/10.1080/08832320903449550

Ogunkola, B.J.; Fayombo, G.A. (2009). Investigating the combined and relative effects of some student-related variables on science achievement among secondary school students in Barbados. European Journal of Scientific Research. 37(3) 481-489.

Simpson, R., Koballa Jr., T., Oliver, J. \& Crawley III, F. (1994). Research on the affective dimension of science learning, in: D. Gabel (Ed.): Handbook of Research on Science Teaching and Learning, pp. 211-234, MacMillan Publishing Company: New York.

Skamp, K; Logan, M. (2005). Students' interest in science across the middle school years. Teaching Science. 51(4), 8-15

Trumper, R (2006). Factors affecting junior high school students' interest in physics. Journal of Science Education and Technology. 15(1). 47-59, http://dx.doi.org/10.1007/s10956-006-0355-6

Table 1. Schools in the sample classified according to category and location

\begin{tabular}{|c|c|c|}
\hline School & Location & Zone \\
\hline Queens College & Urban & 1 \\
St. Lucy Secondary & Rural & 4 \\
St. Michael & Urban & 1 \\
Princess Margaret & Rural & 4 \\
Lodge & Rural & 2 \\
Springer Memorial & Urban & 3 \\
Coleridge and Parry & Rural & 2 \\
St. Leonard's' Boys & Urban & 4 \\
\hline
\end{tabular}

Table 2. Distribution of sample of fourth form students according to school and gender

\begin{tabular}{|l|c|c|c|}
\hline \multirow{2}{*}{ School } & \multicolumn{3}{|c|}{ Number of $4^{\text {th }}$ form Students } \\
\cline { 2 - 4 } & Male & Female & Total \\
\hline Queens College & 10 & 15 & 25 \\
St. Lucy Secondary & 13 & 12 & 25 \\
St. Michael & 10 & 15 & 25 \\
Princess Margaret & 0 & 25 & 25 \\
Lodge & 18 & 7 & 25 \\
Springer Memorial & 12 & 13 & 25 \\
Coleridge and Parry & 18 & 7 & 25 \\
St. Leonard's' Boys & 25 & 0 & 25 \\
\hline Total & 106 & 94 & 200 \\
\hline
\end{tabular}


Table 3. Distribution of sample of teachers according to school and gender

\begin{tabular}{|l|c|c|c|}
\hline \multirow{2}{*}{ School } & \multicolumn{3}{|c|}{ Number of Teachers } \\
\cline { 2 - 4 } & Male & Female & Total \\
\hline Queens College & 3 & 3 & 6 \\
St. Lucy Secondary & 3 & 3 & 6 \\
St. Michael & 3 & 3 & 6 \\
Princess Margaret & 3 & 3 & 6 \\
Lodge & 3 & 3 & 6 \\
Springer Memorial & 3 & 3 & 6 \\
Coleridge and Parry & 3 & 3 & 6 \\
St. Leonard's' Boys & 3 & 3 & 6 \\
\hline Total & 15 & 15 & 30 \\
\hline
\end{tabular}

Table 4. Comparison of topic difficulty indices for students and teachers

\begin{tabular}{|l|c|c|}
\hline Topic & TDI for students & TDI for teachers \\
\hline Neutralization & 11.8 & 13.3 \\
pH / Indicators & 13.5 & 14.3 \\
Characteristics of acids and bases & 14.3 & 0 \\
Nutrients & 6.67 & 0 \\
Food groups & 8.99 & 0 \\
Diet & 7.95 & 0 \\
Reflection and refraction & 11.9 & 14.3 \\
Structure of the eye & 7.46 & 6.70 \\
Eye diseases & 11.5 & 7.14 \\
Properties of sound & 13.7 & 7.69 \\
Structure of the air & 12.5 & 7.69 \\
Role of sound in food laboratory & 38.7 & 0 \\
Composition of the air & 25.3 & 0 \\
Uses of gases in the atmosphere & 23.1 & 0 \\
Chemical tests for gases & 19.0 & 8.33 \\
Role of gases in food preparation and preservation & 37.9 & 0 \\
Heat transfer & 15.4 & 7.69 \\
Forms of energy & 15.3 & 0 \\
Energy transformation & 23.4 & 7.14 \\
Energy conservation & 21.5 & 7.69 \\
Types of chemical reactions & 20.0 & 8.33 \\
Examples of physical and chemical changes in the home & 25.7 & 0 \\
Planning and designing expts on physical and chemical changes & 35.3 & 10.0 \\
Solid waste disposal & 17.3 & 0 \\
Recycling & 12.1 & 0 \\
Pollution & 8.57 & 0 \\
\hline
\end{tabular}


Table 5. Comparison of topic difficulty based on study habits, gender, school location and interest

\begin{tabular}{|l|l|l|l|l|l|l|l|l|}
\hline Variables & Levels & $\mathrm{N}$ & Mean & St.d & $\mathrm{Df}$ & $\mathrm{t}$ & $\mathrm{p}$ & Remarks \\
\hline Study habits & Poor & 58 & 16.70 & 22.96 & 134 & -1.526 & 0.129 & NS \\
& Good & 78 & 10.86 & 16.86 & & & & \\
\hline Sex & Male & 54 & 14.17 & 15.67 & 132 & 0.427 & 0.67 & NS \\
& Female & 80 & 12.67 & 22.33 & & & & \\
\hline School location & Rural & 43 & 13.65 & 21.6 & 134 & 0.495 & 0.621 & NS \\
& Urban & 93 & 11.84 & 15.3 & & & & \\
\hline Interest & Low & 84 & 24.29 & 26.43 & 131 & 5.326 & 0.000 & $*$ \\
& High & 49 & 6.92 & 10.74 & & & & \\
\hline
\end{tabular}

* Significant $(\mathrm{p}<0.0005)$, NS $=$ Not Significant $(\mathrm{p}>0.05)$

Table 6. Comparison of topic difficulty based on school category

\begin{tabular}{|c|c|c|c|c|c|c|c|}
\hline School Category & N & Mean & St.d & df & F & p & Remarks \\
\hline 1 & 44 & 5.1086 & 7.9034 & 3 & 5.906 & 0.001 & $*$ \\
\hline 2 & 25 & 10.8728 & 14.8115 & & & & \\
\hline 3 & 49 & 21.3292 & 26.6388 & & & & \\
\hline 4 & 18 & 13.1911 & 16.3872 & & & & \\
\hline
\end{tabular}

* Significant $(\mathrm{p}<0.0005)$

Table 7. Chi squared analysis of inter-relationships among student variables

\begin{tabular}{|l|c|c|c|c|}
\hline Variables & Pearson chi square & df & Asymptotic sig. & Remarks \\
\hline $\begin{array}{l}\text { School location } \\
\text { Study habits }\end{array}$ & 0.067 & 1 & 0.796 & NS \\
\hline $\begin{array}{l}\text { School location } \\
\text { Interest }\end{array}$ & 0.915 & 1 & 0.339 & NS \\
\hline $\begin{array}{l}\text { School category } \\
\text { Study habits }\end{array}$ & 3.808 & 3 & 0.283 & NS \\
\hline $\begin{array}{l}\text { School category } \\
\text { Interest }\end{array}$ & 5.815 & 3 & 0.121 & NS \\
\hline $\begin{array}{l}\text { Gender } \\
\text { Study habits }\end{array}$ & 0.690 & 1 & 0.406 & NS \\
\hline $\begin{array}{l}\text { Gender } \\
\text { Interest }\end{array}$ & 5.742 & 1 & 0.017 & $*$ \\
\hline $\begin{array}{l}\text { Study habits } \\
\text { Interest }\end{array}$ & 2.530 & 1 & 0.112 & NS \\
\hline
\end{tabular}

* Significant $(\mathrm{p}<0.05)$; NS Not significant

* We acknowledge the involvement of the following in data collection for this study: Rozanne Walrond \& Michaella Charles 